\title{
ANALISA KESEHATAN KEUANGAN PERUSAHAAN \\ DENGAN PENDEKATAN ALTMAN Z-SCORE \\ (STUDI PADA PT ABC TAHUN 2014-2018)
}

\author{
Muhani $^{1}$ \\ Tine Yuliantini ${ }^{2}$ \\ ${ }^{1}$ Fakultas Ekonomi dan Bisnis Universitas Nasional \\ ${ }^{2}$ Fakultas Ekonomi dan Bisnis Universitas Mercu Buana \\ Email: djufrie.rinie@yahoo.com ${ }^{1}$, tineyuliantini@gmail.com ${ }^{2}$
}

\begin{abstract}
ABSTRAK
Penelitian ini bertujuan untuk menganalisis kesehatan keuangan perusahaan dengan pendekatan Altman Z-score, dimana dalam hal ini, studi dilakukan terhadap PT ABC pada periode 2014-2018. Data yang digunakan adalah data sekunder yang berasal dari sumber data internal yang dikumpulkan melalui teknik telaah dokumen.Metode analisis yang digunakan adalah metode kuantitatifyang didasarkan pada rumus yang relevan dalam konsep Altman Z-score.Hasil penelitian menunjukkan bahwa secara rata-rata,PT ABC dapat dikatakan sehat karena memiliki nilai Z-score diatas titik cut-off.
\end{abstract}

Kata kunci: Kinerja keuangan, kesehatan keuangan perusahaan, Altman Z-score

\section{ABSTRACT}

This research aims to analyze the financial health of the company using Altman Z-score approach, where in this case, the study was conducted on PT ABC in the 2014-2018 period. The data used was secondary data from internal data resources that collected through document review techniques. The analytical method used was quantitative method based on the relevant formula in the Altman Z-scoreconcept. The results showed that on average, PT ABC is said to be healthy because it has a Z-score above the cut-off point.

Keywords: Financial performance, financial health of the company, Altman Z-score

\section{PENDAHULUAN}

Pertumbuhan ekonomi yang melebihi 5\%, peningkatan jumlah kelas menengah, serta pembangunan jalan tol berbayar dan jalan umum secara terus-menerus diyakini akansemakin mendongkrak penjualan kendaraan bermotor di masa mendatang.Terlebih lagi, industri otomotif itu sendiri merupakan salah satu dari lima sektor manufaktur yang pengembangannya kini sedang diprioritaskan oleh pemerintah untuk dijadikan sebagai salah satu pionir penerapan revolusi industri keempat sesuai dengan programnya yang bertajuk "Peta Jalan Making Indonesia 4.0”.

Agar mampu untuk bertahan dan senantiasa berkembang dalam industri otomotif yang kian kompetitif dan kompleks, maka perusahaan dituntut untuk senantiasa 
meningkatkan kinerja keuangannya.Terkait dengan hal ini, kemampuan perusahaan dalam memprediksi kemampuan keuangannya di masa mendatang juga diperlukan untuk memperkecil risiko kebangkrutan dari perusahaan.Hal tersebut dapat dilakukan melalui analisis kesehatan keuangan yang disebut juga dengan istilah analisis diskriminan Altman, yakni suatu model statistik yang merumuskan rasio-rasio finansial terbaik untuk memprediksi kebangkrutan perusahaan berdasarkan Z-score yang dirumuskan dari rasiorasio itu sendiri.

PT ABC merupakan perusahaan swasta yang bergerak di bidang industri otomotif, yakni dealer resmi Honda di Jakarta Selatan, yang memiliki beberapa bidang usaha yang terdiri dari penjualan mobil, penjualan sparepart mobil, General Repair, dan Body Paint. Selama periode 2014-2018, kondisi keuangan PT ABCterus mengalami fluktuasi sebagaimana yang dapat dilihat pada tabel 1 berikut ini.

Tabel 1.Kondisi Keuangan PT ABCTahun 2014-2018

(dalam Jutaan Rupiah)

\begin{tabular}{|c|c|c|c|c|c|}
\hline Keterangan & 2014 & 2015 & 2016 & 2017 & 2018 \\
\hline Aktiva & $\operatorname{Rp} 21,752$ & $\operatorname{Rp} 31,900$ & $\operatorname{Rp} 26,238$ & $\operatorname{Rp} 48,579$ & Rp 50,538 \\
\hline Kewaj & Rp 16,546 & $\operatorname{Rp} 22,455$ & Rp 13,073 & $\operatorname{Rp} 30,133$ & $\operatorname{Rp} 32,308$ \\
\hline Laba & $\mathrm{Rp} \quad 1,084$ & $\mathrm{Rp} 4,238$ & $\mathrm{Rp} 3,720$ & $\mathrm{Rp} \quad 4,855$ & $\mathrm{Rp} \quad(216)$ \\
\hline
\end{tabular}

(Sumber: Laporan Keuangan PT ABC)

Identifikasi masalah di atas memberikan gambaran untuk melakukan analisis terhadap PT ABC dalam hal penilaian kesehatan keuangan perusahaan, sehingga disusunlah penelitian ini yang berjudul "Analisa Kesehatan Keuangan Perusahaan dengan Pendekatan Altman Z-score (Studi pada PT ABC Tahun 2014-2018)”.

\section{TINJAUAN PUSTAKA}

\section{Kinerja Keuangan}

Kinerja keuangan merupakan suatu ukuran atas tingkat keberhasilan perusahaan dalam mengelola sumber daya keuangannya.Hal ini sesuai dengan yang diungkapkan oleh Munawir(2002) yang mendefinisikan kinerja keuangan sebagai kemampuan dari suatu perusahaan dalam menggunakan modal yang dimiliki secara efektif dan efisien guna mendapatkan hasil yang maksimal.Adapun menurut IAI (2009),kinerja keuangan diartikan sebagai kemampuan perusahaan dalam mengelola dan mengendalikan sumberdaya yang dimilikinya. 
Berdasarkan definisi-definisi diatas, dapat disimpulkan bahwa kinerja keuangan merupakan suatu usaha formal yang telah dilakukan oleh perusahaan yang dapat mengukur keberhasilan perusahaan dalam menghasilkan laba, sehingga dapat melihat prospek, pertumbuhan, dan potensi perkembangan baik perusahaan dengan mengandalkan sumber daya yang ada.

\section{Analisis Laporan Keuangan}

Laporan keuangan merupakan pernyataan yang mencerminkan pengumpulan, tabulasi, dan ringkasan akhir dari data akuntansi (Kieso, et al.,2010).Didalam PSAK 2014 No. 1 paragraf 5 disebutkan bahwa tujuan umum dari suatu laporan keuangan adalah memberikan informasi mengenai posisi keuangan, kinerja dan arus kas perusahaan yang bermanfaat bagi sebagian besar kalangan pengguna laporan dalam rangka membuat keputusan-keputusan ekonomi serta menunjukkan pertanggungjawaban (stewardship) manajemen atas penggunaan sumber-sumber daya yang dipercayakan kepada mereka (IAI, 2009).

Analisis laporan keuangan pada dasarnya dilakukan untuk mengetahui tingkat profitabilitas dan risiko atau bahkan tingkat kesehatan dari suatu perusahaan(Hanafi, 2004).Dalam pelaksanaannya, analisis laporan keuangan umumnya dilakukan dengan menggunakan rasio keuangan sebagai alat utamanya. Menurut Keown (2004), rasio keuangan itu sendiri dapat dipergunakan untuk menjawab sekurang-kurangnya empat pertanyaan, yakni mengenai likuiditas perusahaan, efektivitas manajemen dalam menghasilkan laba operasi atas aset yang dimilikinya, sumber pendanaan perusahaan, serta kecukupan tingkat pengembalian yang diterima oleh pemegang saham biasa.

\section{Analisis Z-Score}

Menurut Supardi (2003) dalam Rahadi dan Sufyati (2019), Altmanadalah suatu diskriminan yang dipergunakan untuk memprediksi kebangkrutan dari suatu perusahaan dengan mempergunakan Z-score,yakni skor hitung dari standar kali atas berbagai rasio keuangan yang menunjukkan probabilitas kebangkrutan dari suatu perusahaan. Analisis ZScoreitu sendiri merupakan suatu analisis yang dapat dipergunakan untuk mengetahuiada atau tidaknya gejala ketidaksehatan perusahaan yang nantinya memungkinkan manajemen untuk memprediksi prospek perusahaan dalam menjaga keberlangsungan hidupnya.Dalam 
hal ini, semakin besar nilai Z, maka semakin besar pula jaminanatas keberlangsungan hidup dari suatu perusahaan dan sebaliknya, semakin kecil risiko kegagalan dari perusahaan tersebut.

Dalam analisis Altman Z-score, nilai $\mathrm{Z}$ dapat dicari dengan persamaan diskriminan sebagai berikut.

$$
\mathrm{Zi}=1,2 \mathrm{X}_{1}+1,4 \mathrm{X}_{2}+3,3 \mathrm{X}_{3}+0,6 \mathrm{X}_{4}+1,0 \mathrm{X}_{5}
$$

(Sumber: Altman, 1968)

Keterangan:

$$
\begin{aligned}
& \mathrm{X}_{1}=\text { Working capitaltototal asset } \\
& \mathrm{X}_{2}=\text { Retained earningtototal asset } \\
& \mathrm{X}_{3}=\text { Earning before interest and tax tototal asset } \\
& \mathrm{X}_{4}=\text { Market value of equity tobook value of total debt } \\
& \mathrm{X}_{5}=\text { Sales tototal asset } \\
& \mathrm{Zi}=\text { Z-Score }
\end{aligned}
$$

Z-score yang dihasilkan dari rumus di atas, selanjutnyaakan dikelompokkan ke dalam tiga kategori sebagai berikut.

Tabel 2. Titik Cut-Off dalam Model Altman Z-Score dengan Nilai Pasar

\begin{tabular}{|l|l|}
\hline \multicolumn{1}{|c|}{ Kategori } & \multicolumn{1}{c|}{ Titik Cut-Off } \\
\hline Tidak bangkrut & $\mathrm{Z}>2,99$ \\
\hline Bangkrut & $\mathrm{Z}<1,81$ \\
\hline Daerah rawan & $1,81<\mathrm{Z}<2,99$ \\
\hline
\end{tabular}

(Sumber: Hanafi dan Halim, 2007:275)

Apabila perusahaan yang dianalisis belum go-public, maka nilai pasar dalam rumus Altman Z-Score pada model pertama dapat diganti menggunakan nilai buku saham biasa dan preferen. Berdasarkan ketentuan tersebut, dikembangkan model sebagai berikut.

$$
\mathrm{Zi}=\mathbf{0 , 7 1 7} \mathrm{X}_{1}+\mathbf{0 , 8 4 7} \mathrm{X}_{2}+\mathbf{3 , 1 0 7} \mathrm{X}_{3}+\mathbf{0 , 4 2} \mathrm{X}_{4}+\mathbf{0 , 9 9 8} \mathrm{X}_{5}
$$

(Sumber: Altman, 1983)

Keterangan:

$$
\begin{aligned}
& \mathrm{X}_{1}=\text { Working capitaltototal asset } \\
& \mathrm{X}_{2}=\text { Retained earningtototal asset } \\
& \mathrm{X}_{3}=\text { Earning before interest and tax tototal asset } \\
& \mathrm{X}_{4}=\text { Book value of equity tobook value of total debt }
\end{aligned}
$$




$$
\begin{aligned}
& \mathrm{X}_{5}=\text { Sales tototal asset } \\
& \mathrm{Zi}=\text { Z-Score }
\end{aligned}
$$

Z-score yang dihasilkan dari rumus di atas, selanjutnyaakan dikelompokkan ke dalam tiga kategori sebagai berikut.

Tabel 3. Titik Cut-Off dalam Model Altman Z-Score dengan Nilai Buku

\begin{tabular}{|l|l|}
\hline \multicolumn{1}{|c|}{ Kategori } & \multicolumn{1}{c|}{ Titik Cut-Off } \\
\hline Tidak bangkrut & $\mathrm{Z}>2,90$ \\
\hline Bangkrut & $\mathrm{Z}<1,20$ \\
\hline Daerah rawan & $1,20<\mathrm{Z}<2,90$ \\
\hline
\end{tabular}

(Sumber: Hanafi dan Halim, 2007:275)

\section{Kerangka Analisis}

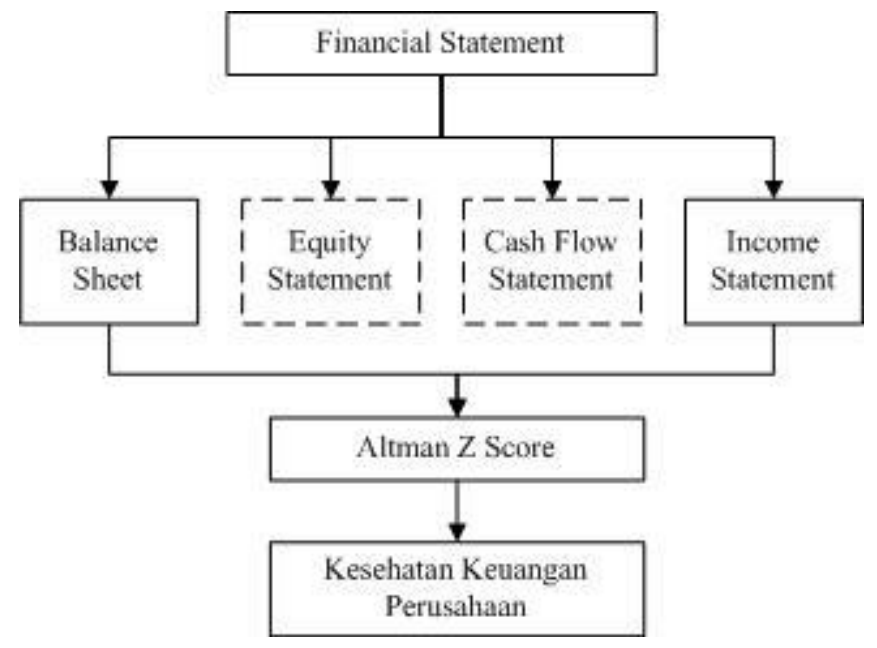

Gambar 1. Kerangka Analisis

Keterangan gambar:

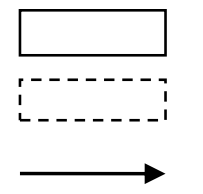

: Data/variabel yang menjadi fokus bahasan

: Data/variabel yang tidak menjadi fokus bahasan

: Garis yang menghubungkan kepada data/variabel yang menjadi fokus bahasan 


\section{METODOLOGI PENELITIAN}

\section{Objek Penelitian}

Objek penelitian ini adalah kesehatan keuangan perusahaan dengan PT ABCsebagai subjek penelitian.Dalam hal ini, periode 2014-2018 digunakan sebagai periode waktu yang diteliti karena laba yang diperoleh perusahaan pada periode tersebut terbukti mengalami fluktuasi.

\section{Sumber dan Jenis Data}

Jenis data yang digunakan dalam penelitian ini adalah data sekunder dan time series dengan sumber data internal, yakni berupa laporan keuangan PT ABC pada periode 2014-2018.Data tersebut dikumpulkan dengan menggunakan teknik telaah dokumen.

\section{Metode Analisis}

Metode analisis yang digunakan adalah metode kuantitatifyang didasarkan pada rumus yang relevan dalam konsep Altman Z-score.

\section{HASIL DAN PEMBAHASAN}

\section{Analisis Rasio}

\section{Modal Kerja terhadap Total Aset $\left(\mathrm{X}_{1}\right)$}

Data modal kerja terhadap total aset PT ABC pada periode 2014-2018 dapat dilihat pada tabel sebagai berikut.

Tabel 4.Modal Kerja terhadap Total Aset

PT ABC Periode 2014-2018 (dalam Jutaan Rupiah)

\begin{tabular}{|l|r|r|r|r|r|}
\hline \multicolumn{1}{|c|}{ Keterangan } & \multicolumn{1}{c|}{$\mathbf{2 0 1 4}$} & \multicolumn{1}{c|}{$\mathbf{2 0 1 5}$} & \multicolumn{1}{|c|}{$\mathbf{2 0 1 6}$} & \multicolumn{1}{c|}{$\mathbf{2 0 1 7}$} & \multicolumn{1}{c|}{$\mathbf{2 0 1 8}$} \\
\hline Total aktiva lancar & 16,634 & 25,197 & 19,586 & 41,596 & 43,163 \\
\hline Total utang lancar & 15,277 & 20,991 & 11,302 & 27,736 & 29,067 \\
\hline Modal kerja & 1,356 & 4,207 & 8,284 & 13,860 & 14,096 \\
\hline Total aset & 21,752 & 31,900 & 26,238 & 48,579 & 50,538 \\
\hline Rasio modal kerja terhadap total aset & $\mathbf{6 . 2 3 \%}$ & $\mathbf{1 3 . 1 9 \%}$ & $\mathbf{3 1 . 5 7 \%}$ & $\mathbf{2 8 . 5 3 \%}$ & $\mathbf{2 7 . 8 9 \%}$ \\
\hline
\end{tabular}

(Sumber: Data diolah, 2019)

Berdasarkan data diatas, modal kerja terhadap total aset PT ABC pada periode20142018terbukti mengalami fluktuasi.Pada tahun 2014-2016,rasiomodal kerja terhadap total aset terlihat mengalami peningkatan. Hal ini disebabkan oleh hal-hal sebagai berikut. 
a. Peningkatan aktiva lancar lebih besar daripada peningkatan utang lancar dan total aktiva pada tahun 2014-2015, yaitu aktiva lancar meningkat sebanyak 51\% sedangkan utang lancar meningkat sebanyak $37 \%$ dan total aktiva meningkat sebanyak $47 \%$.

b. Penurunan utang lancar lebih besardaripada penurunan aktiva lancar dan total aktiva pada tahun 2015-2016, yaitu utang lancar menurun sebanyak 46\% sedangkan aktiva lancar menurun sebanyak $22 \%$ dan total aktiva menurun sebanyak $18 \%$.

Sementara itu, rasiomodal kerja terhadap total aset PT ABC justru mengalami penurunan pada tahun 2016-2018.Hal ini disebabkan oleh sebagai berikut.

a. Pada tahun 2016-2017, utang lancar meningkat sebanyak 145\% sedangkan aktiva lancar meningkat sebanyak $112 \%$ dan total aktiva meningkat sebanyak $85 \%$

b. Pada tahun 2017-2018, utang lancar meningkat sebanyak 5\% sedangkan aktiva lancar meningkat sebanyak $4 \%$ dan total aktiva meningkat sebanyak $4 \%$.

Dengan demikian, PT ABC harus dapat menjaga peningkatan kewajiban lancarnya pada tingkat yang lebih rendah dibandingkan dengan peningkatan aktiva lancarnya.Hal ini bisa dilakukan dengan menekan agar nilai biaya yang masih harus dibayar pada akhir tahunmenjadi lebih rendah, yakni melalui pembayaran kewajiban lancar secara tepat waktu.Hal lain yang harus dilakukan oleh perusahaan adalah mempertimbangkan penambahan pendanaan untuk kebutuhan jangka panjang dengan menggunakan fasilitas ekuitas atau menambah kewajiban jangka panjangnya.

\section{Laba Ditahan terhadap Total Aset $\left(\mathbf{X}_{2}\right)$}

Data laba ditahan terhadap total aset dari PT ABC pada periode 2014-2018 dapat dilihat pada tabel sebagai berikut.

Tabel 5.Laba Ditahan terhadap Total Aset

PT ABC Periode 2014-2018 (dalam Jutaan Rupiah)

\begin{tabular}{|l|r|r|r|r|c|}
\hline \multicolumn{1}{|c|}{ Keterangan } & $\mathbf{2 0 1 4}$ & $\mathbf{2 0 1 5}$ & $\mathbf{2 0 1 6}$ & $\mathbf{2 0 1 7}$ & $\mathbf{2 0 1 8}$ \\
\hline Laba ditahan & 3,073 & 7,311 & 11,031 & 15,886 & 15,670 \\
\hline Total aset & 21,752 & 31,900 & 26,238 & 48,579 & 50,538 \\
\hline Rasio laba ditahan terhadap total aset & $\mathbf{1 4 . 1 3 \%}$ & $\mathbf{2 2 . 9 2 \%}$ & $\mathbf{4 2 . 0 4 \%}$ & $\mathbf{3 2 . 7 0 \%}$ & $\mathbf{3 1 . 0 1 \%}$ \\
\hline
\end{tabular}

(Sumber: Data diolah, 2019) 
Berdasarkan data diatas, rasio laba ditahan terhadap total aset PT ABC pada periode 2014-2018 terbukti mengalami fluktuatif. Pada tahun 2014-2016, rasio tersebut terlihat mengalami peningkatan.Hal ini disebabkan oleh hal-hal sebagai berikut.

a. Peningkatan laba ditahan lebih besar daripada peningkatan total aktiva pada tahun 2014-2015, yaitu laba ditahan meningkat sebanyak 138\% sedangkan total aktiva meningkat sebanyak $47 \%$.

b. Laba ditahan mengalami peningkatan, sedangkan total aktiva mengalami penurunan pada tahun 2015-2016, yaitu laba ditahan meningkat sebanyak 51\% sedangkan total aktiva menurun sebanyak $18 \%$.

Sementara itu pada tahun 2016-2018,rasio laba ditahan terhadap total aset justru terlihat mengalami penurunan. Hal ini disebabkan oleh hal-hal sebagai berikut.

a. Peningkatan laba ditahan lebih kecil daripada peningkatan total aktiva pada tahun 2016-2017, yaitu laba ditahan meningkat sebanyak 44\% sedangkan total aktiva meningkat sebanyak $85 \%$.

b. Laba ditahan mengalami penurunan, sedangkan total aktiva mengalami peningkatan pada tahun 2017-2018, yaitu laba ditahan menurun sebanyak 1\% sedangkan total aktiva meningkat sebanyak $4 \%$.

Dengan demikian, PT ABC telah menunjukkan bahwa aktiva yang digunakan dalam operasionalnya telah cukup baik dalam menghasilkan laba, yang mana dalam hal ini merupakan laba yang tidak dibagikan kepada pemegang saham.

\section{EBIT terhadap Total Aset $\left(\mathbf{X}_{3}\right)$}

Data rasio EBIT terhadap total aset dari PT ABC pada periode 2014-2018 dapat dilihat pada tabel sebagai berikut.

Tabel 6.EBIT terhadap Total Aset

PT ABC Periode 2014-2018 (dalam Jutaan Rupiah)

\begin{tabular}{|l|r|r|r|r|r|}
\hline \multicolumn{1}{|c|}{ Keterangan } & \multicolumn{1}{c|}{$\mathbf{2 0 1 4}$} & \multicolumn{1}{c|}{$\mathbf{2 0 1 5}$} & \multicolumn{1}{c|}{$\mathbf{2 0 1 6}$} & \multicolumn{1}{c|}{$\mathbf{2 0 1 7}$} & \multicolumn{1}{c|}{$\mathbf{2 0 1 8}$} \\
\hline EBIT & 1,769 & 5,326 & 5,091 & 6,600 & $(182)$ \\
\hline Total aset & 21,752 & 31,900 & 26,238 & 48,579 & 50,538 \\
\hline Rasio EBIT terhadap total aset & $\mathbf{8 . 1 3 \%}$ & $\mathbf{1 6 . 7 0 \%}$ & $\mathbf{1 9 . 4 0 \%}$ & $\mathbf{1 3 . 5 9 \%}$ & $\mathbf{- 0 . 3 6 \%}$ \\
\hline
\end{tabular}

(Sumber: Data diolah, 2019) 
Berdasarkan data di atas, rasio EBIT terhadap total aset PT ABC pada periode 2014-2018 terbukti mengalami fluktuasi. Pada tahun 2014-2016, nilai EBITterhadap total aset terlihat mengalami peningkatan.Hal ini disebabkan oleh hal-hal sebagai berikut.

a. Peningkatan EBITlebih besar daripada peningkatan total aktiva pada tahun 20142015, yaitu EBIT meningkat sebanyak 201\% sedangkan total aktiva meningkat sebanyak $47 \%$.

b. Penurunan total aktiva lebih besar daripada penurunan EBIT pada tahun 20152016, yaitu EBIT menurun sebanyak 4\% sedangkan total aktiva menurun sebanyak $18 \%$.

Sementara itu pada tahun 2016-2018,rasioEBITterhadap total aset dari PT ABC justru terlihat mengalami penurunan.Hal ini disebabkan oleh hal-hal sebagai berikut.

a. Peningkatan EBIT lebih kecil daripada peningkatan total aktiva pada tahun 20162017, yaitu EBIT meningkat sebanyak 30\% sedangkan total aktiva meningkat sebanyak $85 \%$.

b. EBIT mengalami penurunan bahkan bernilai negatif sedangkan total aktiva mengalami peningkatan pada tahun 2017-2018, yaitu EBIT menurun sebanyak $103 \%$ sedangkan total aktiva meningkat sebanyak $4 \%$.

Dengan demikian, PT ABC telah menunjukkan bahwa aktiva yang digunakan dalam operasionalnya kurang baik dalam menghasilkan laba, terutama pada tahun 2018.

\section{Nilai Buku Modal terhadap Nilai Buku Utang $\left(\mathbf{X}_{4}\right)$}

Data rasio nilai buku modal terhadap nilai buku utangdari PT ABC pada periode 2014-2018 dapat dilihat pada tabel sebagai berikut.

Tabel 7.Nilai Buku Modal terhadap Nilai Buku Utang

PT ABC Periode 2014-2018 (dalam Jutaan Rupiah)

\begin{tabular}{|l|r|r|r|r|r|}
\hline \multicolumn{1}{|c|}{ Keterangan } & $\mathbf{2 0 1 4}$ & $\mathbf{2 0 1 5}$ & $\mathbf{2 0 1 6}$ & $\mathbf{2 0 1 7}$ & $\mathbf{2 0 1 8}$ \\
\hline Nilai buku ekuitas & 2,133 & 2,133 & 2,133 & 2,560 & 2,560 \\
\hline Nilai buku utang & 16,546 & 22,455 & 13,073 & 30,133 & 32,308 \\
\hline $\begin{array}{l}\text { Rasio nilai buku modal terhadap nilai } \\
\text { buku utang }\end{array}$ & $\mathbf{1 2 . 8 9 \%}$ & $\mathbf{9 . 5 0 \%}$ & $\mathbf{1 6 . 3 2 \%}$ & $\mathbf{8 . 5 0 \%}$ & $\mathbf{7 . 9 2 \%}$ \\
\hline
\end{tabular}

(Sumber: Data diolah, 2019)

Berdasarkan data diatas, rasio nilai buku modal terhadap nilai buku utangdari PT ABC pada periode 2014-2018 terbukti mengalami fluktuasi.Pada tahun 2015-2016,rasio 
tersebut terlihat mengalami peningkatan. Hal ini disebabkan olehadanya penurunan total utangsebanyak $42 \%$, sementara modal saham justru tidak berubah. Sementara pada tahun 2014-2015 dan 2016-2018, rasio nilai buku modal terhadap nilai buku utangdari PT ABC justru terlihat mengalami penurunan.Hal ini disebabkan oleh hal-hal sebagai berikut.

a. Peningkatan utangsementara modal sahamnya tetap pada tahun 2014-2015 dan 2017-2018, yaitu utang meningkat sebanyak 36\% pada tahun 2015 dan 7\% pada tahun 2018.

b. Peningkatan utang lebih besar daripada peningkatan modal saham pada tahun 2016-2017, yaitu utang meningkat sebanyak 130\%, sedangkan modal sahammeningkat sebanyak $20 \%$.

Dengan demikian, PT ABC harus dapat menjaga peningkatan utang pada tingkat yang lebih rendah dibandingkan dengan peningkatan modal sahamnya.Apabila kewajiban jangka panjang lebih besar daripada modal saham, maka hal tersebut menunjukkan bahwa sebagian besar operasional PT ABC didanai oleh kewajiban jangka panjang, sehingga risiko default atau ketidakmampuannyadalam membayar kewajiban yang ditanggung pun menjadi tinggi. Sebaliknya, apabila nilai modal saham lebih tinggi daripada nilai kewajiban jangka panjangnya, maka sebagian besar operasional PT ABC didanai dari modal saham perusahaan itu sendiri.Kondisi ideal dari segi rasio ini adalah kondisi dimana PT ABC didanai lebih banyak dari modal saham, bukan dari pihak ketiga sehingga risiko default-nya semakin rendah.

\section{Penjualan terhadap Total Aset $\left(\mathbf{X}_{5}\right)$}

Data rasio penjualan terhadap total aset dari PT ABC pada periode 2014-2018 dapat dilihat pada tabel sebagai berikut.

Tabel 8.Penjualan terhadap Total Aset

PT ABC Periode 2014-2018 (dalam Jutaan Rupiah)

\begin{tabular}{|l|r|r|r|r|r|}
\hline \multicolumn{1}{|c|}{ Keterangan } & \multicolumn{1}{|c|}{$\mathbf{2 0 1 4}$} & \multicolumn{1}{c|}{$\mathbf{2 0 1 5}$} & \multicolumn{1}{|c|}{$\mathbf{2 0 1 6}$} & \multicolumn{1}{c|}{$\mathbf{2 0 1 7}$} & \multicolumn{1}{c|}{$\mathbf{2 0 1 8}$} \\
\hline Penjualan & 112,237 & 175,331 & 167,258 & 192,999 & 279,992 \\
\hline Total aset & 21,752 & 31,900 & 26,238 & 48,579 & 50,538 \\
\hline Rasio penjualan terhadap total aset & $\mathbf{5 1 5 . 9 9 \%}$ & $\mathbf{5 4 9 . 6 3 \%}$ & $\mathbf{6 3 7 . 4 6 \%}$ & $\mathbf{3 9 7 . 2 9 \%}$ & $\mathbf{5 5 4 . 0 3 \%}$ \\
\hline
\end{tabular}

(Sumber: Data diolah, 2019)

Berdasarkan data diatas, rasio penjualan terhadap total aset dari PT ABC pada periode 2014-2018 terbukti mengalami fluktuasi. Pada tahun 2014-2016 dan 2017-2018, 
nilai rasio tersebut terlihat mengalami peningkatan.Hal ini disebabkan oleh hal-hal sebagai berikut.

a. Peningkatan penjualan lebih besar daripada peningkatan total aktiva pada tahun 2014-2015 dan 2017-2018, yaitu penjualan meningkat sebanyak 56\%, sedangkan total aktiva meningkat sebanyak $47 \%$ pada tahun 2014-2015, serta pada tahun 2017-2018, penjualan meningkat sebanyak 45\%, sedangkan total aktiva meningkat sebanyak $4 \%$.

b. Penurunan total aktiva lebih besar daripada penurunan penjualan pada tahun 20152016, yaitu penjualan menurun sebanyak 5\%,sedangkan total aktiva menurun sebanyak $18 \%$.

Sementara itu pada tahun 2016-2017, rasio penjualan terhadap total aset justru terlihat mengalami penurunan. Hal ini disebabkan oleh adanya peningkatan penjualanyang lebih kecil daripada peningkatan total, yaitu penjualanhanya meningkat sebanyak $15 \%$,sementara total aktiva justru meningkat sebanyak $85 \%$.

Dengan demikian, rasio perputaran total aktiva yang mengalami kenaikan setelah sempat menurun mengindikasikan bahwa PT ABC telah memiliki kemampuan yang semakin baik dalam menggunakan seluruh aktivanya untuk menghasilkan penjualan serta semakin efisien dalam menggunakan seluruh aktiva yang dimilikinya tersebut untuk menghasilkan laba.

\section{Analisis Z-Score}

Dalam analisis ini, rumus Altman Z-score yang dipergunakan adalah rumus dengan nilai buku, yakni dengan model lengkap sebagai berikut.

$$
\mathrm{Zi}=\mathbf{0 , 7 1 7} \mathrm{X}_{1}+\mathbf{0 , 8 4 7} \mathrm{X}_{2}+\mathbf{3 , 1 0 7} \mathrm{X}_{3}+\mathbf{0 , 4 2} \mathrm{X}_{4}+\mathbf{0 , 9 9 8} \mathrm{X}_{5}
$$

Berdasarkan model tersebut, diperoleh nilai $Z$-score dalam tabel sebagai berikut.

Tabel 9. Z-Score PT ABC Periode 2014-2018

\begin{tabular}{|l|r|r|r|r|r|}
\hline \multicolumn{1}{|c|}{ Keterangan } & $\mathbf{2 0 1 4}$ & \multicolumn{1}{c|}{$\mathbf{2 0 1 5}$} & \multicolumn{1}{c|}{$\mathbf{2 0 1 6}$} & \multicolumn{1}{c|}{$\mathbf{2 0 1 7}$} & \multicolumn{1}{c|}{$\mathbf{2 0 1 8}$} \\
\hline Rasio modal kerja terhadap total aset & 0.06 & 0.13 & 0.32 & 0.29 & 0.28 \\
\hline Bobot & 0.717 & 0.717 & 0.717 & 0.717 & 0.717 \\
\hline Rasio laba ditahan terhadap total aset & 0.14 & 0.23 & 0.42 & 0.33 & 0.31 \\
\hline Bobot & 0.847 & 0.847 & 0.847 & 0.847 & 0.847 \\
\hline Rasio EBIT terhadap total aset & 0.081 & 0.167 & 0.194 & 0.136 & $(0.004)$ \\
\hline Bobot & 3.107 & 3.107 & 3.107 & 3.107 & 3.107 \\
\hline $\begin{array}{l}\text { Rasio nilai buku ekuitas terhadap nilai } \\
\text { buku dari utang }\end{array}$ & 0.129 & 0.095 & 0.163 & 0.085 & 0.079 \\
\hline
\end{tabular}




\begin{tabular}{|l|r|r|r|r|r|}
\hline Bobot & 0.42 & 0.42 & 0.42 & 0.42 & 0.42 \\
\hline Rasio pendapatan terhadap total asset & 5.16 & 5.50 & 6.37 & 3.97 & 5.54 \\
\hline Bobot & 0.998 & 0.998 & 0.998 & 0.998 & 0.998 \\
\hline Z-score & $\mathbf{5 . 6 2}$ & $\mathbf{6 . 3 3}$ & $\mathbf{7 . 6 2}$ & $\mathbf{4 . 9 0}$ & $\mathbf{6 . 0 1}$ \\
\hline
\end{tabular}

(Sumber: Data diolah, 2019)

Berdasarkan tabel diatas, diketahui bahwa Z-Score PT ABC selama periode 20142018 memiliki nilai di atas 2,90, sehingga perusahaan tersebut terbukti merupakan perusahaan yang sehat atau tidak sedang mengalami kesulitan keuangan. Meskipun demikian, perusahaan juga harus senantiasa berhati-hati dalam menjalankan bisnisnya karena nilai dari rasio $\mathrm{X}_{1}$ s.d. $\mathrm{X}_{4}$ selama tiga tahun terakhir menunjukkan adanya penurunan.Apabila permasalahan pada rasio tersebut tidak segera diatasi, maka cepat atau lambat perusahaan tersebut kemungkinan akan mengalami kesulitan keuangan.

\section{KESIMPULAN DAN SARAN}

\section{Kesimpulan}

Berdasarkan hasil penelitian ini, dapat disimpulkan hal-hal sebagai berikut.

1. Berdasarkan rasio modal kerja terhadap total aset, perusahaandapat dikatakan likuid dari segi keuangan.

2. Berdasarkan rasio laba ditahan terhadap total aset dan rasio EBIT terhadap total aset, perusahaandapat dikatakan efisien.

3. Berdasarkan rasio nilai buku modal terhadap nilai buku utang, perusahaan dapat dikatakan kurang solvabel.

4. Berdasarkan rasio penjualan terhadap total aset, perusahaan dapat dikatakan sangat menguntungkan.

5. Secara keseluruhan, keuangan perusahaan berada dalam kondisi yang sehat.

\section{Saran}

Berikut ini merupakan saran yang diberikan berdasarkan hasil penelitian.

1. Dari sisi pendanaan, sebaiknya PT ABC lebih banyak menggunakan modal. Dalam hal ini, apabilaperusahaan bermaksud untuk menambah utang, maka ekuitasnya juga perlu ditambah terlebih dahulu.

2. Dari sisi kemampulabaan, masalah utama yang dihadapi oleh PT ABC adalah bagaimana mengelola alokasi biaya operasionalnya agar lebih terkendali, sehingga 
kemampulabaannya dapat dioptimalisasi. Dalam hal ini, perlu dilakukan pemusatan perhatian pada program Cost Reduction and Restructuring yang harus segera dilaksanakan.

3. Walaupun tergolong sehat, perusahaan diharapkan untuk memperbaiki kinerja keuangannya mengingat kinerja keuangan perusahaan tersebut terbukti mengalami penurunan secara berturut-turut selama tiga tahun dan bahkan mengalami kerugian pada tahun 2018 .

4. Para peneliti selanjutnya diharapkan dapat melalukan penelitian pada perusahaan dagang di sektor lain atau pada perusahaan manufaktur karena Model Altman ZScoreitu sendiri dapat dipergunakan pada semua jenis perusahaan. Selain itu, peneliti selanjutnya juga diharapkan dapat menggunakan model-model prediksi kebangkrutan lainnya selain Altman Z-Score.

\section{DAFTAR PUSTAKA}

Altman, E.I. 1968. Financial Ratios, Discriminant Analysis and the Prediction of Bankruptcy. The Journal of Finance. 23(4): 589-609. . 1983. Corporate Financial Distress: A Complete Guide to Predicting, Avoiding and Dealing with Bankruptcy. Wiley and Sons. New York.

Halim, A. dan M.M. Hanafi. 2007. Analisis Laporan Keuangan. UPP STIM YKPN. Yogyakarta.

Hanafi, M.M. 2004. Manajemen Keuangan. BPFE.Yogyakarta.

Ikatan Akuntan Indonesia. 2009. Standar Akuntansi Keuangan. Salemba Empat. Jakarta.

Keown, A.J. 2004.Manajemen Keuangan: Prinsip-Prinsip dan Aplikasi. PT Indeks Kelompok Gramedia. Jakarta.

Kieso, D.E., J.J. Weygandt, dan P.D. Kimmel. 2010. Financial Accounting. IFRS Edition.John Wiley \& Sons Asia.Singapore.

Munawir, S. 2002. Analisis Laporan Keuangan. Bumi Aksara.Jakarta.

Rahadi, A.P. dan H.S. Sufyati. 2019. Analisis Financial Distress pada Bank Umum Syariah di Indonesia. Jurnal Ilmu Manajemen Oikonomia. 15(1): 98-110.

Supardi, S.M. 2003. Validitas Penggunaan Z Score Altman untuk Menilai Kebangkrutan pada Perusahaan Perbankan yang Go Public di Bursa Efek Jakarta. KOMPAK. (7): 68-93. 